\title{
Compromiso, voluntad y respeto por los valores para iniciar un nuevo siglo
}

\author{
Commitment, will and respect for the values to enter a new century of the \\ Sociedad Argentina de Pediatría
}

Hace muy poco tiempo nos reunimos para celebrar los 100 años de nuestra Sociedad, un hito digno de destacar por el crecimiento y la labor desarrollada, habida cuenta de las dificultades que suelen existir en nuestro país para mantener un proyecto a largo plazo, y que fueron festejados con alegría, pero también con reflexión.

Fue el corolario de un camino previo que incluyó numerosas actividades científicas, sociales y culturales, y que alcanzó su máxima expresión en el Congreso del Centenario.

En el transcurso de este primer siglo la SAP fue construyendo una estructura sólida, basada en las ideas preclaras de algunos, pero sustentada principalmente en el esfuerzo de todos sus integrantes, entregando las respuestas adecuadas en relación con las necesidades y desafíos de cada momento apoyándose en sus fortalezas: la idoneidad, el conocimiento y la permanente defensa de los derechos de niños y adolescentes.

Y lo hizo sosteniendo siempre valores y convicciones que son perdurables, y fueron imprescindibles para superar momentos muy difíciles de nuestra historia.

Muchos cambios se han sucedido durante este tiempo, con un avance vertiginoso del conocimiento y la tecnología, intensas modificaciones sociales y una explosión en el campo de las comunicaciones, que generan realidades cambiantes y a las cuales es necesario adaptarse con la rapidez adecuada.

En la Pediatría en particular, ha habido un enorme desarrollo de recursos preventivos y terapéuticos, que han posibilitado evitar y dar respuestas terapéuticas a enfermedades antes mortales; sin embargo, no existe un correlato respecto de la velocidad con que se atienden las necesidades urgentes de la infancia.

Se mantienen enormes inequidades, evidenciadas por las diferencias en la morbimortalidad materno infantil entre países ricos y pobres, reaparecen enfermedades ligadas con la pobreza y el desamparo social, a pesar de algunas acciones positivas auspiciosas; la marginalidad, con las dificultades en el acceso a la Educación, y como consecuencia al trabajo, favorece principalmente en los adolescentes, situaciones que abonan el te- rreno para las adicciones, la incursión en actividades delictivas por mencionar algunas.

Persiste el flagelo que significa el trabajo infantil, y la Convención de los Derechos del Niño producida hace más de 20 años sigue siendo un instrumento básico declamado pero no ejecutado de manera efectiva.

Por otra parte, ese salto tecnológico mencionado ha mejorado la sobrevida, pero ha originado, como contrapartida, nuevas enfermedades con una gran cantidad de pacientes crónicos, algunos con pobre calidad de vida, y dilemas éticos de difícil resolución.

Hoy me toca el honor de asumir como el primer Presidente del segundo siglo de existencia de la Sociedad Argentina de Pediatría, después de haber participado activamente durante más de 20 años, inicialmente en el Comité de Terapia Intensiva, y luego desempeñando distintos cargos en sucesivas Comisiones Directivas.

Un largo tiempo que me permitió consustanciarme con los valores que antes mencionaba, y adquirir real conciencia de la magnitud de su importancia como entidad de consulta permanente en todos los asuntos que competen a la infancia, pero también en la riqueza del intercambio con colegas de todo el país y en la valoración del disenso como elemento fundamental en el crecimiento como profesional.

Cuento con este bagaje para conducir junto con mis compañeros de Comisión Directiva este período que tendrá algunas características particulares en la marcha de la Sociedad: este año se aprobó una modificación de sus Estatutos, con el propósito de adecuar la organización al crecimiento incesante y adecuarla a los cambios, hecho necesario para mantenerla como una entidad dinámica y viva.

Las dos variantes más significativas son la obtención de la personería jurídica por parte de todas las Filiales, lo cual redundará en un mejor ordenamiento y desarrollo, y el acortamiento de los mandatos a dos años, tanto de la Comisión Directiva central como de las Regiones, Filiales, Comités, Grupos de trabajo y Subcomisiones.

Esta última circunstancia hace imperativo el trabajo intenso y la proyección de objetivos a largo plazo, al mismo tiempo que permite mayor 
recambio y disminuye el desgaste para quienes deben desarrollar su actividad profesional y dedicar muchas horas a la Sociedad en forma honoraria.

Asimismo implicará la reorganización de los Congresos y Eventos, en la que lo más importante es que el Congreso Argentino de Pediatría volverá a ser bianual.

En consonancia con el contexto planteado inicialmente, continuaremos con la producción, apoyo y ejecución de proyectos compartidos con instituciones gubernamentales y ONG, tratando de obtener impactos sociales y sanitarios duraderos que puedan morigerar la inequidad, en el convencimiento de que este es un eje político indeclinable que debe mantener la SAP.

Para ello es imprescindible la activa participación de las Regiones, gestionando y produciendo propuestas que reflejen las distintas realidades que ofrece nuestro país, una contribución que es decisiva y constituye una de las mayores de nuestras fortalezas: nuestra estructura federal, que debe ser sostenida y acrecentada.

Para ello vamos a brindar apoyo decidido a las Filiales para que continúen e intensifiquen la labor que llevan a cabo, tanto en el aspecto docente cuanto en su presencia en la comunidad.

Contamos con medios de comunicación que nos permitirán tener un contacto más estrecho y frecuente, y mayor capacidad resolutiva consensuada.

Tenemos la obligación de intensificar nuestro rol protagónico en la formación de los Pediatras, a través de nuestra Red Nacional de Educación Continua, con la convicción de que deben ser eficaces agentes de prevención y promoción de la salud, con una sólida formación científica que les permita enfrentar los nuevos problemas que se suscitan con el natural progreso del conocimiento.

Pero a esto debe sumarse un fuerte contenido ético, la jerarquización de la relación médico-paciente-familia y una actitud abierta para el ejercicio interdisciplinario, indispensable en todos los niveles de atención.

Es nuestro deber proporcionar el estímulo y los elementos para el desarrollo de la investigación, cualquiera sea el lugar en que al pediatra le toque desempeñarse, e incorporar conceptos que favorezcan la mejoría en la calidad de la atención y la prevención del error, una verdadera enfermedad cuya prevalencia es mayor que muchas de las patologías a las que dedicamos mayor atención, y que produce una considerable morbimortalidad.

Pero es muy claro que esta expectativa de formación de un pediatra que sea capaz de actuar de acuerdo con las necesidades actuales debe ser acompañada de condiciones dignas de trabajo para quien las ejerce, que incluyan una remuneración adecuada, con instituciones que ofrezcan una estructura que contemple los recursos técnicos que hacen falta, la seguridad laboral que está ausente en muchos ámbitos y la posibilidad de disponer de espacios para mantener su actualización.

Estamos ante un escenario difícil para el ejercicio profesional, situación que es un motivo de preocupación para la SAP desde hace años, y en esta dirección se han tomado distintas decisiones para analizar posibles acciones. Hace tres años se creó la Subcomisión de Ejercicio Profesional, se llevaron a cabo talleres en distintos lugares y las Primeras Jornadas que ya se han incorporado al calendario de Eventos.

En un proyecto conjunto con UNICEF se concretó una encuesta de satisfacción y características del ejercicio profesional entre los pediatras de la SAP que está en fase final de procesamiento, y alguno de cuyos resultados preliminares fueron presentados en el Congreso del Centenario.

Creemos que será un instrumento útil para objetivar esta realidad y elaborar propuestas ante quienes tienen la posibilidad y la obligación de modificarla.

Este es un camino que vamos a seguir transitando con toda nuestra energía; nos legitima nuestra función de médicos de cabecera de niños y adolescentes, y como consecuencia, los naturales efectores de las acciones en salud.

Asumimos un gran compromiso, el de conducir una Sociedad de enorme prestigio, con la responsabilidad de acrecentarlo. Estoy seguro de que lo haremos, como decía Albert Einstein, con una fuerza motriz más poderosa que el vapor, la electricidad y la energía atómica: la voluntad.

$$
\text { Dr. Gustavo Cardigni }
$$

Presidente

Sociedad Argentina de Pediatría

http:/ /dx.doi.org/10.5546/aap.2012.2 